\title{
Effects of a Static Synchronous Series Compensator (SSSC) Based on a Soft Switching 48-Pulse PWM Inverter on the Power Demand from the Grid
}

\author{
Taha Selim Ustun ${ }^{\dagger}$ and Saad Mekhilef* \\ †* Department of Electrical Engineering, University Malaya, Kuala Lumpur, Malaysia
}

\begin{abstract}
In this paper the effects of a Static Synchronous Series Compensator, which is constructed with a 48-pulse inverter, on the power demand from the grid are studied. Extensive simulation studies were carried out in the MATLAB simulation environment to observe the compensation achieved by the SSSC and its effects on the line voltage, line current, phase angle and real/reactive power. The designed device is simulated in a power system which is comprised of a three phase power source, a transmission line, line inductance and load. The system parameters such as line voltage, line current, reactive power Q and real power P transmissions are observed both when the SSSC is connected to and disconnected from the power system. The motivation for modeling a SSSC from a multi-pulse inverter is to enhance the voltage waveform of the device and this is observed in the total harmonic distortion (THD) analysis performed at the end of the paper. According to the results, the power flow and phase angle can be controlled successfully by the new device through voltage injection. Finally a THD analysis is performed to see the harmonics content. The effect on the quality of the line voltage and current is acceptable according to international standards.
\end{abstract}

Key Words: FACTS, H-bridge Inverter, Matlab simulation, Multi-pulse, Power flow control, Power line compensation, PWM inverter, Quasi-resonant

\section{INTRODUCTION}

Power plants and load centers are pooled in today's interconnected power systems to minimize the total power generation capacity along with the generation costs. This is also done to improve the reliability of the grid since the transmission interconnections can take advantage of different types of load, source availabilities and fuel prices [1]. Accordingly the electric energy supply systems of the contemporary world are interconnected on a wide scale. They are growing radially from intra-utility connections in their respective regions to inter-utility connections with other utilities and finally to international connections that bind the energy systems of different countries.

The power lines are loaded more heavily since the utility companies prefer to rely on existing generation and power export/import arrangements instead of building new transmission lines that are subject to environmental and regulatory policies. There are several reasons behind this including a variety of environmental, land-use and regulatory pressures as well as the high cost of new power line construction. For these reasons, although the amount of the power transmitted over power lines, power demand of the loads, access by the third parties to the lines and the bulk power transfers are increasing with every

\footnotetext{
Manuscript received Mar. 16, 2009; revised Oct. 17, 2009

†Corresponding Author: tahaselim@yahoo.com

Tel: +60-14-3202881, University Malaya

* Dept. of Electrical Engineering, University Malaya, Malaysia
}

single day, the growth of electric power transmission facilities in many parts of the world is restricted [2].

Furthermore, with increasing power transfers and heavier loading, power systems become gradually more complex to operate and they may become less secure for riding out major power outages [2], [4]. As a result, large power flows with inadequate control may be observed and excessive reactive power and large dynamic swings may be experienced in different parts of the system which will prevent the transmission interconnections from being fully utilized [1].

It is important to note that transmission lines operate way below their thermal limits. This is because, in the past, before the appearance of semi-conductor based switches the dynamic changes occurring in lines could not be compensated immediately as there was no device which could switch fast enough for this purpose. Instead the transients occurring due to dynamic changes in the lines were suppressed and/or compensated by large operating margins [1]-[3]. However, with the latest technology incorporating solid state switches much faster and more reliable control of lines is possible. This in turn opens the way for loading the interconnected systems heavier and thus utilizing them closer to their full capacity [3]. In order to address these issues an extensive method of power flow control over the interconnected systems is needed. Flexible AC Transmission Systems (FACTS) are the devices that respond to these needs by significantly altering the way transmission systems are developed and controlled together 
with improvements in asset utilization, system flexibility and system performance [5]. Various FACTS devices are used to dynamically control the voltage, impedance and phase angle of high voltage AC transmission lines. This in turn makes it possible to operate a transmission line closer to its thermal capacity thus increasing its transmission capacity. This also makes it possible to change the impedance of the transmission lines and thus control the power flow and to damp and filter undesired transients over the transmission system [4], [6].

Due to their significance, a wide range of research on FACTS devices has been performed. The optimal location of FACTS devices [7], control strategies [8], their impact on power systems [9] and the connection of renewable energy systems to the grid with the help of FACTS devices [10] can be counted as general research topics in this field. A Static Synchronous Series Compensator (SSSC) is a specific type of FACTS device and the main focus of this paper. It has also been a popular research subject. The analyses of different topologies such as 12-pulse [11] and 48-pulse inverters [12], based on a voltage source converter [13] or a current source converter [14] and their dynamic characteristics have been performed. Furthermore, controller implementation for stabilization and better performance has also been a very dynamic research field with proposed enhanced controllers for different kinds of topologies or utilization purposes [15], [16].

This study is mainly concerned with the design of a SSSC with a 48-pulse PWM inverter and the simulation of its compensation characteristics over a modeled power line. The motivation in utilizing a multi-pulse inverter is to increase the quality of the output waveform. The compensation of the reactive power $\mathrm{Q}$ over the power lines and the allocation of a larger portion of the overall power transmission capacity to the real power $\mathrm{P}$ is the ultimate goal of the designed system. In addition to that, a quasi-resonant circuit is used at the dc supply side. This circuit changes the constant DC voltage to a pulse which attains a zero-voltage level for a short period of time. This is done to create an interval where soft switching of the IGBTs in the inverter can be realized. Detailed information on this circuit can be found in [18] whereas its performance and compatibility with 48-pulse inverters was studied by the same authors in [19].

\section{SySTEM CONFIGURATION}

A three phase source, a line inductance characterizing the power lines and a three phase load at the receiving end are used to model a power system, as shown in Fig. 1. The bus B1, connecting the three phase source to the power line measures the voltage supplied by the source and the current demanded by the system. From these measured values the instantaneous real $(\mathrm{P})$ and reactive $(\mathrm{Q})$ power flows are worked out and thus the power flow over the power system and the compensation, if any, by the SSSC are calculated. The positions of the buses B1 and B2 are important. Because they are placed before and after, respectively, the transmission line inductances and the transformer connecting the SSSC to the power system the affect of the compensation can be observed.

The power source is set to generate a $230 \mathrm{kV}$ three phase voltage at $50 \mathrm{~Hz}$. This value is selected so that the simulated power system emulates a long transmission line or a high voltage transmission line [17] depending on the classification method used. A purely inductive load is used in this example since most of the industrial loads, such as electrical machines, can be characterized with inductive loads.

There are two sub-blocks in the hierarchy of SSSC. One of them is a quasi-resonant dc supply which is used to provide soft switching. This has been studied in detail as referred to earlier in [18] and [19]. The other one is a closed loop control, shown in Figure 2, which is used for synchronization, compensation and PWM signal generation.

The quasi-resonant topology is used in the system is a deviated DC supply, in the sense that the output of this supply is not a constant dc value but rather a dc value that occasionally goes down to zero whenever the resonance is triggered. This is useful for the realization of the zero voltage switching technique to reduce switching losses over the semi-conductor switches. This topology was designed exclusively for quasiresonance purposes [18] and its compatibility with H-bridge IGBT multi-pulse inverters has also been investigated in detail [19]. It is also used in extensive power system simulations [23].

The closed loop control shown below is used to determine the phase angle of the line current flowing over the transmission line. Then a phase shift of pi/2 radians is applied and the PWM signals triggering the inverters used in the multipulse inverter are generated from these data by the designed PWM generator. The PWM generator generates sine waves with the angle given and it then generates the PWM signals by comparing these signals with the carrier frequency according to the value of the modulation index. This closed loop control operates SSSC in "compensation for power flow" mode, a classification put forth by Hingorani and Gyugi [1].

The section that is enclosed by the broken line is an optional control which can be utilized to enhance the control of the Q-flow over the line. However, it is not indispensable as far as the implementation of a SSSC is concerned since the ultimate target of the compensation is to decrease the reactive power flow over the line and thus increase the real power flow capacity. The ideal case for a purely inductive load, which necessitates capacitive compensation, is attained when the former is minimized so as to maximize the latter. This ideal case can be achieved when the phase shift is 90 degrees and all of the injected voltage is capacitive. Throughout the simulation studies this idealized control loop is used to decrease the calculation load on the computer.

\section{Simulation Results}

The circuit is simulated to observe the free (uncontrolled) power flow over the line. The real power P demanded by the load is supplied by the three phase source and transmitted by the transmission line between B1 and B2. The simulations were performed to see the power demands, voltage and current supplied by the source, transmitted by the line and received by the load. Following these observations a Static Synchronous Series Compensator (SSSC) is operated to decrease the Q-flow over the line by compensating the reactive power demanded by the system. 


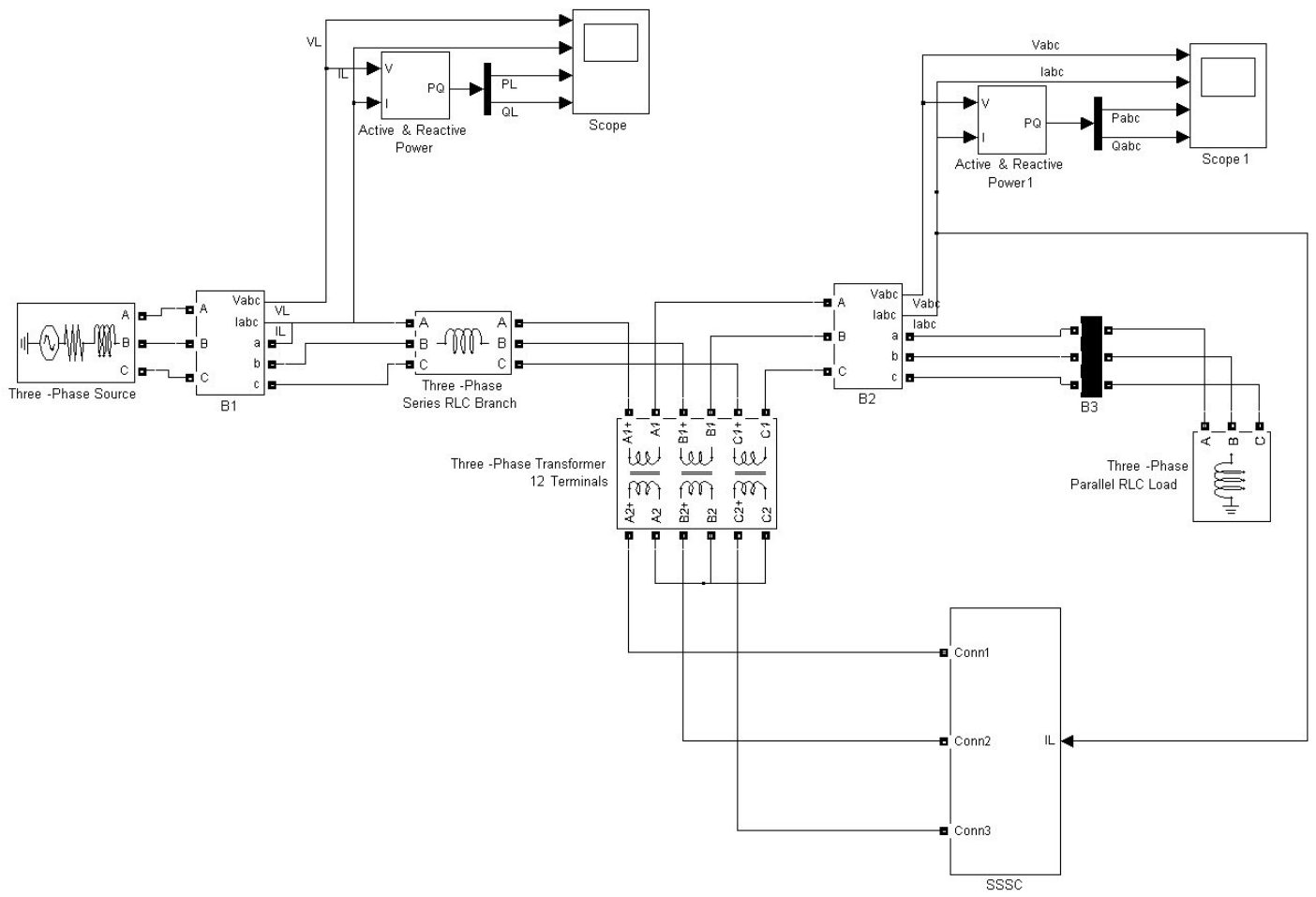

Fig. 1. Simulated Power Line and SSSC.

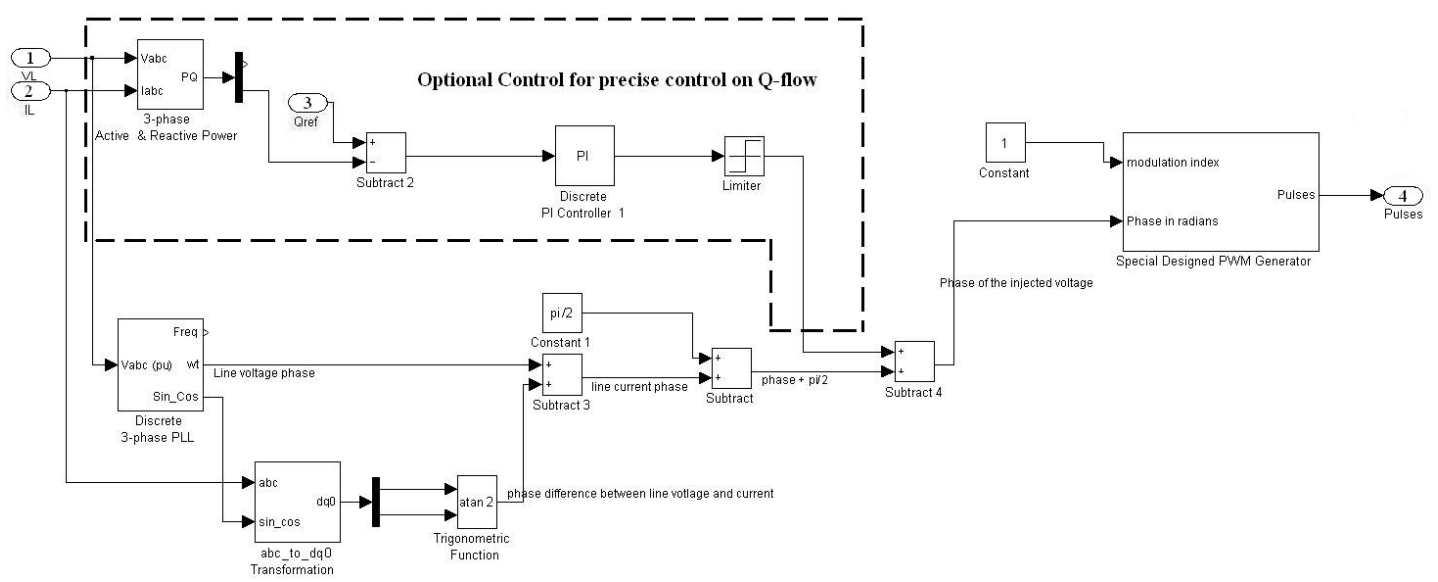

Fig. 2. Simulated Power Line and SSSC.

First the simulations were carried out when the SSSC was switched off. The three phase source voltage and current waveforms along with the real and reactive power flows were obtained as shown in Fig. 3. The same parameters were observed after switching on the SSSC and the waveforms shown in Fig. 4 were obtained. The signal over the feedback loop and the control signals for the closed loop control are given in Fig. 5 whereas the output voltage of the multi-pulse inverter, which is the voltage that is injected into the line, is given in Fig. 6.

Analyzing the results and the waveforms it can be easily said that the synchronization and compensation are performed satisfactorily by the designed SSSC. The feedback signal which is generated from the line current flowing over the power line is used to generate the PWM signals. This way both synchronization and a 90 degree phase difference with the line current are achieved.

In order to interpret the results, a comparative approach would be appropriate for the waveforms obtained before and after the SSSC is operated. The line voltage and current shown in Fig. 3 clearly depict the phase difference between them induced by the inductive current drawn by the system which decreases the power factor of the source side. Accordingly the reactive power $\mathrm{Q}$ drawn from the source reaches considerable values. The level of the real power $\mathrm{P}$ should also be noted here in order to compare it with the value obtained under the compensation condition.

After turning on the SSSC the effect of the compensation is 


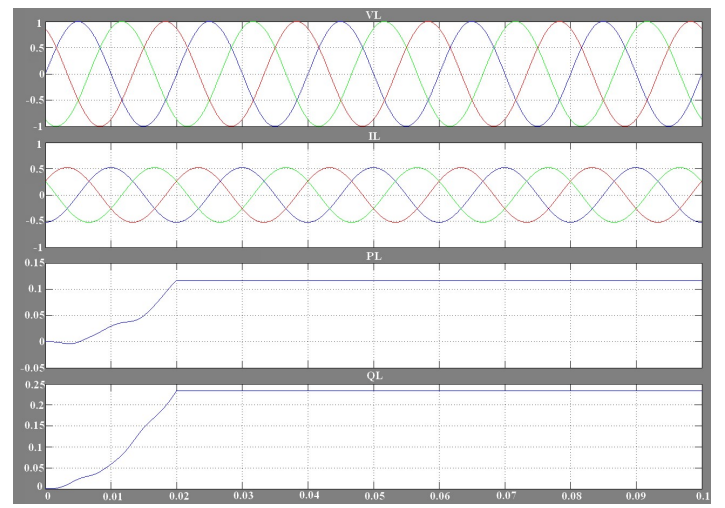

Fig. 3. Three phase Source Voltage, Current, Real and Reactive Powers (SSSC OFF).

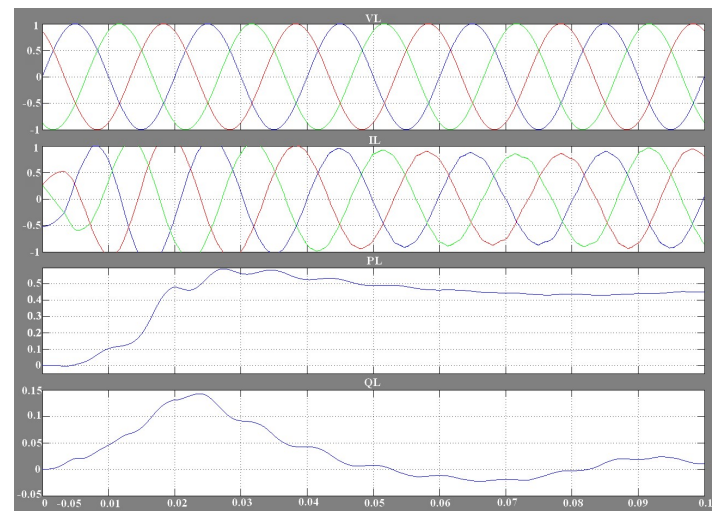

Fig. 4. Three phase Source Voltage, Current, Real and Reactive Powers (SSSC ON).

evident from the decreasing phase difference between the three phase line voltage and the current. The phase difference can be controlled with the relevant control on the SSSC by means of the control loop shown earlier. Since the line current is not lagging as much as it did under non-compensation condition, the reactive power flow $\mathrm{Q}$ over the line is reduced considerably. The flow of reactive power is not only decreased over the line but also from the overall power demanded from the three phase power source. In short the reactive power demand is met by the output voltage of the SSSC.

Returning to the fundamental motivation for series compensation, the reactive power flow $\mathrm{Q}$ over the transmission line

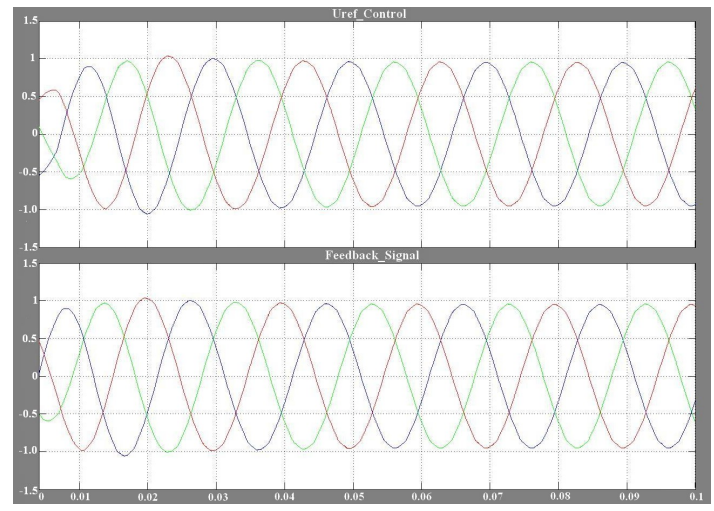

Fig. 5. Feedback Signal and Uref control signal for PWM generation.

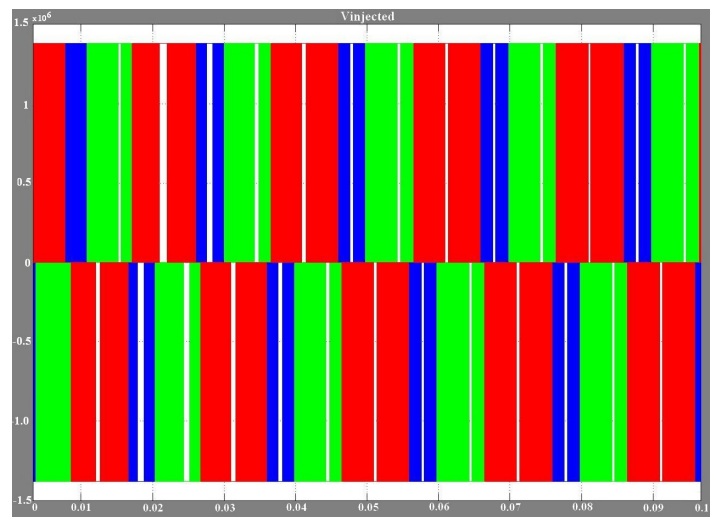

Fig. 6. Injected Voltage by the SSSC (Inverter Output Voltage).

TABLE I

EFFECTS OF SSSC COMPENSATION

\begin{tabular}{|c|c|c|c|c|c|}
\hline $\begin{array}{c}\text { SSSC } \\
\text { STATUS }\end{array}$ & $\begin{array}{c}\text { Phase } \\
\text { difference }\end{array}$ & $\begin{array}{c}\text { Psource } \\
\text { (pu) }\end{array}$ & $\begin{array}{c}\text { Qsource } \\
\text { (pu) }\end{array}$ & $\begin{array}{c}\text { P/Q of } \\
\text { ratio } \\
\text { capacity } \\
\text { allocated } \\
\text { for P }\end{array}$ \\
\hline OFF & $60^{\circ}$ & 0.12 & 0.24 & 0.5 & 44.72 \\
\hline ON & $2^{\circ}$ & 0.45 & 0.024 & 22.5 & 99.2 \\
\hline
\end{tabular}

is desired to be as low as possible so that the transmission capacity can be allocated to the power demand of the load. Considering Fig. 3 and Fig. 4 a rise in the real power transmission P to the same load with the same source settings and the same line voltage waveform can be observed.

The effects of the compensation are summarized in Table 1 where it can be clearly seen that the real power $\mathrm{P}$ transmission from the source to the load becomes five times larger whereas the reactive power $\mathrm{Q}$ demanded from it is reduced to one third of its previous value. These changes are obviously the results of the phase difference that is caused by the compensation which reduces the $60^{\circ}$ of line current lagging to a mere $2^{\circ}$. Looking at the overall real and reactive power ratio it is observed that the ratio has improved ten times. When the apparent power is calculated from the equation [20]:

$$
S^{2}=P^{2}+Q^{2}
$$

and calculating the ratio of the allocated real power transmission capacity to that of apparent power, it is seen that the allocation percentage has almost doubled. Consequently another aspect of compensation is realized and simulated with success.

The phasor diagram given above in Fig. 7 is a method of depicting the compensation and the effect of the injected voltage in a visual manner. It is not only descriptive but

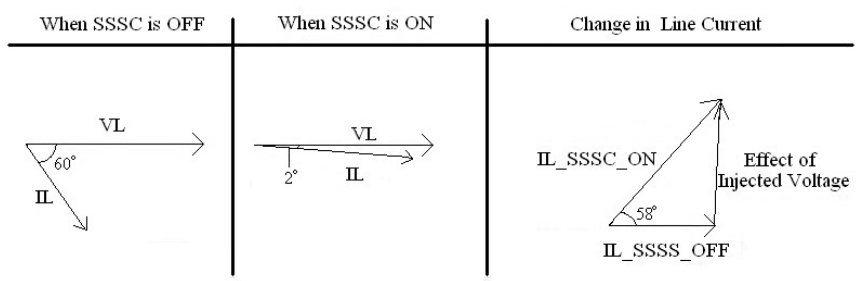

Fig. 7. Line Voltage and Current Phasor Diagrams. 


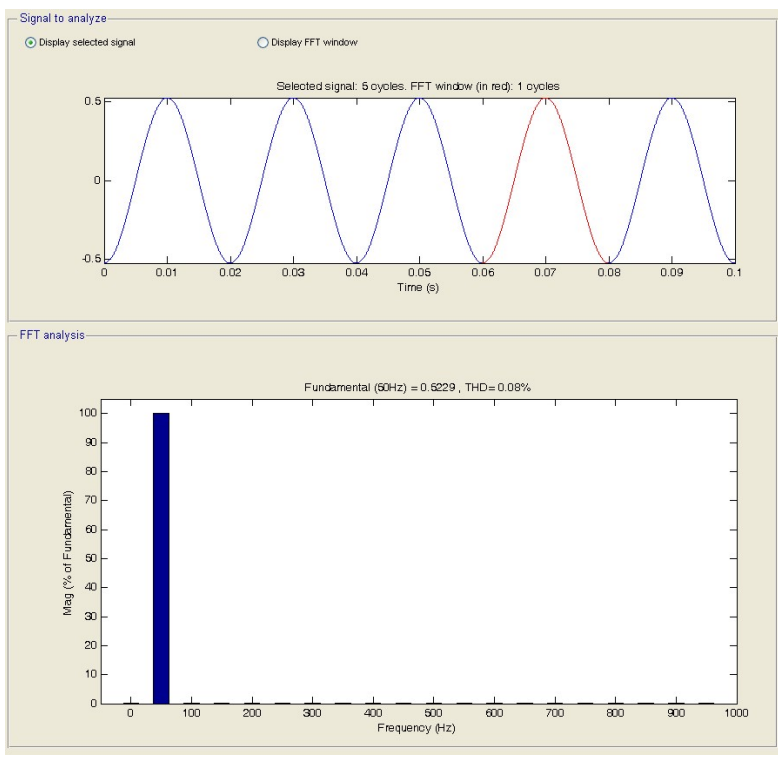

Fig. 8. Line Current THD Analysis (at Bus B1 - SSSC OFF).

also lucid and therefore it is widely used in power system analysis. On the left the three phase voltage and current phasor diagram for a non-compensated network is given. Due to the line inductance the current drawn from the source has a phase difference with the voltage supplied by it and, as expected, the phase difference is inductive. Consequently the line current is lagging the line voltage. When the SSSC is turned on the compensation decreases the effect of the line inductance and, as a result, the phase difference between the line voltage and current decreases. This in turn, obviously, decreases the reactive power supplied by the source. Should it be desired, it is possible to increase the amount of compensation and the line current flows in phase with the line voltage which makes the reactive power flow zero. The compensation may be increased further and a capacitive transmission line appears in front of the three phase source. In this simulation, to be more realistic and to see the compensation, total negation of the inductive effect of the line inductance is not implemented.

One of the biggest challenges in inverter grid connection and voltage injection studies is the appearance of harmonic distortion due to the injected voltage and/or current [21]. In order to assess the quality of the line current, total harmonic distortion THD analyses of the line currents are performed both under the compensated and the non-compensated conditions. The results for the THD analyses are presented in Fig. 8 to Fig. 11.

The figures show that the injected voltage has a negative effect on the harmonic distortion of the line current. However, in spite of the change in the THD value, the compensated current has a very low harmonic content and is acceptable according to harmonic rules and regulations [22].

\section{CONCLUSions}

A Static Synchronous Series Compensator (SSSC) is constructed from a conventional 48-pulse inverter and a detailed closed loop control is designed to control the power flows over power lines. The designed device is connected to the receiving

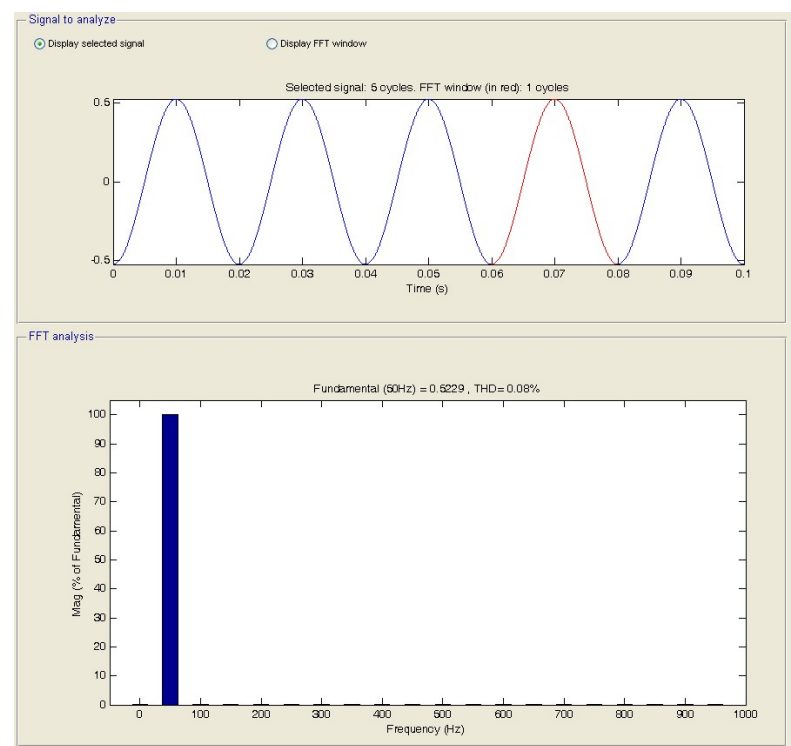

Fig. 9. Line Current THD Analysis (at Bus B2 - SSSC OFF).

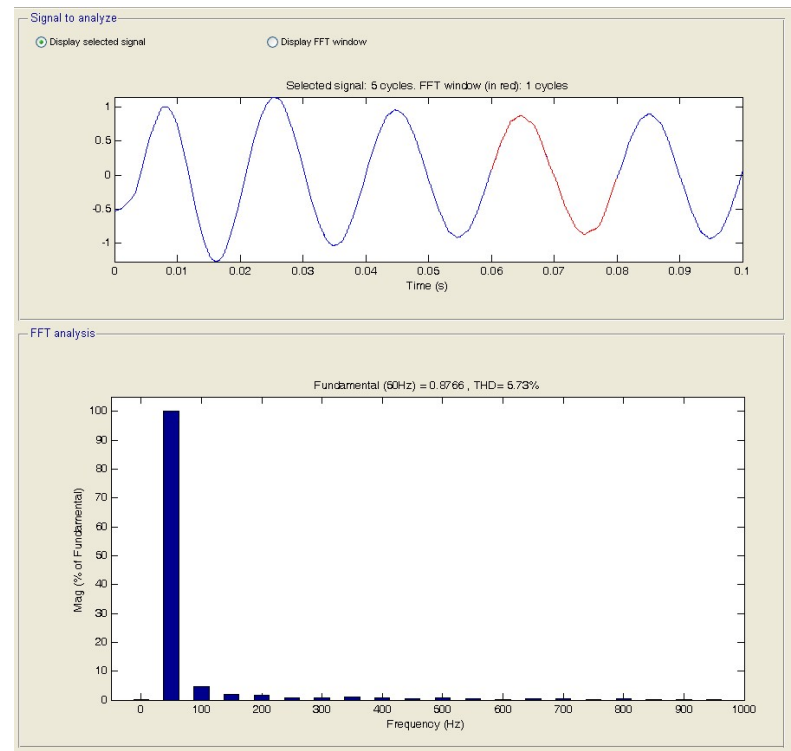

Fig. 10. Line Current THD Analysis (at Bus B1 - SSSC ON).

end of a modeled power system and its operation is verified by a series of simulations in the MATLAB environment. The obtained results proved to be satisfactory. The Total Harmonic Distortion (THD) studies performed both when the SSSC is on and off show that the harmonic content introduced to the line current is very low. This is due to the utilization of a multi-pulse inverter in the construction of the device, which inherently filters harmonics up to certain levels and thus enhances the output waveform quality.

The voltage and current waveforms along with the instantaneous active and reactive power calculations reveal that the designed topology works satisfactorily. The reactive power flow over the power line is compensated with the help of series injected voltage by the SSSC. The balance or the stability of the system is not affected and the harmonic distortion is kept at a reasonable level thanks to the multi-pulse inverter used in the construction of the device. 


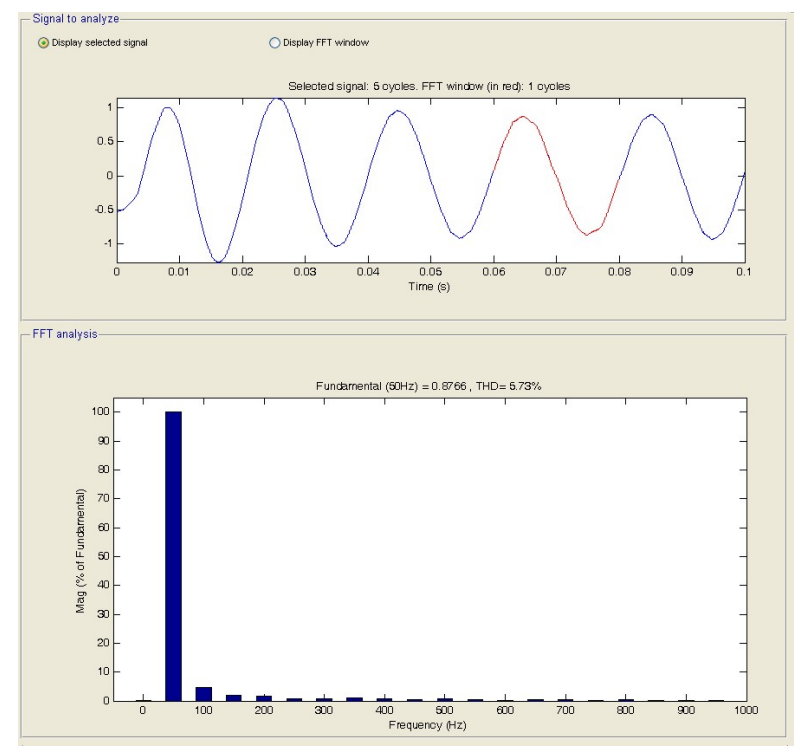

Fig. 11. Line Current THD Analysis (at Bus B2 - SSSC ON).

\section{REFERENCES}

[1] Hingorani N., Gyugyi L., "Understanding FACTS, Concepts and Technology of Flexible AC Transmission Systems,” IEEE Press, pp. 1-2 1999.

[2] Asare P., Diez T, Galli A., O'Neill-Carillo E., Robertson J., Zhao R., "An Overview of Flexible AC Transmission Systems," ECE Technical Reports PURDUE University, 1994.

[3] Ying X., Song Y.H., Chen-Ching L., Sun Y., "Available Transfer Capability Enhancement Using FACTS Devices," IEEE Transactions on Power Systems, Vol. 18, No. 1, Feb. 2003.

[4] Paserba J., "How FACTS Controllers Benefit AC Transmission Systems," Transmission and Distribution Conference and Exposition, PES 2003.

[5] Habur K., Leary D.O., "FACTS for Cost Effective and Reliable Transmission of Electrical Energy," Reactive Power Compensation, Power Transmission and Distribution Group of Siemens, 2005.

[6] Singer A., Hoffman W., "Combined System of the Static Synchronous Series Compensator and Passive Filter Applied to Wind Energy Conversion System," Proceedings of PEDS 2007, Nov. 2007.

[7] Mahdad B., Barek T., Srairi K., "Strategy of Location and Control of FACTS Devices for Enhancing Power Quality," Proceedings of IEEE Melecon 2006, May 2006.

[8] Lin Z., Zexiang C., Yixin N., Zhou L., Deqiang G., "A Novel Controller Design for STATCOM Based On The Concept Of Area Center Of Inertia," Third International Conference on Electric Utility Deregulation and Restructuring and Power Technologies, pp. 1281-1286, Apr. 2008.

[9] Galiana F.D., Almeida K., Toussaint M., Griffin J., Atanackovic D., Ooi B.T., McGillis D.T., "Assessment and Control Of The Impact Of Facts Devices On Power System Performance," IEEE Transactions on Power Systems, Vol. 11, No. 4, Nov. 1996.

[10] Molinas M., Kondoh J., Suul J.A., Undeland T., "Reactive Support For Wind And Wave Farms With A Statcom For Integration Into The Power System," Proceedings of Renewable Energy Conference 2006, Oct. 2006.

[11] Padiyar K.R., Prabhu N., "Analysis of SubSynchronous Resonance with Three Level Twelve-Pulse VSC based SSSC," Proceedings of TENCON 2003, Oct. 2003.
[12] Geethalaksmi B., Hajmunnisa T., Dananjayan P., "Dynamic Characteristic Analysis of SSSC based on 48-pulse Inverter," Proceedings of IPEC 2007, Dec. 2007.

[13] Han B., Moon S., Karady G., "Dynamic Characteristic Analysis of Multi-bridge PWM Inverter for SSSC," Power Engineering Society Summer Meeting, IEEE, Vol. 3, pp. 1618-1623, Jul. 2000.

[14] Ye Y., Kazerani M., Quintena V., "SSSC: Current-Source Converter Based Modeling and Control," Power Engineering Society Summer Meeting IEEE, Vol. 2, 15-19, pp. 949-954, Jul. 2001.

[15] Zhao Y., Xiao X., Jia X., "Nonlinear PID Controller of H-Bridge Cascade SSSC Top Level Control," Third International Conference on Electric Utility Deregulation and Restructuring and Power Technologies, Apr. 2008.

[16] El-Moursi M.S., Sharaf A.M., "Novel Controllers for the 48-Pulse VSC STATCOM and SSSC for Voltage Regulation and Reactive Power Compensation," IEEE Transactions on Power Systems, Vol. 20, No. 4, Nov. 2005

[17] Wildi T., "Electrical Machines, Drives and Power Systems," Second Edition, Prentice Hall, pp.596-598, 1991.

[18] Hui S.Y.R et al., "Analysis of a Quasi-Resonant Circuit for SoftSwitched Inverters," IEEE Transactions of Power Electronics, vol. 11, no 1, pp. 106-114, Jan. 1996.

[19] Ustun T.S., Mekhilef S., "A Quasi-Resonant Soft Switching 48-pulse PWM inverter with closed loop current control for the realization of FACTS devices," Proceedings of Australasian Universities Power Engineering Conference AUPEC '08, Dec. 2008.

[20] Mohan N., Undeland T., Robbins W., "Power Electronics, Converter, Applications, and Design," John Wiley and Sons, 1995.

[21] Kisck D. O., Navrapescu, V., Kisck M., "Single-Phase Unified Power Quality Conditioner with Optimum Voltage Angle Injection for Minimum VA requirement," Power Electronics Specialists Conference, Jun. 2007.

[22] IEEE, "Recommended Practice for Utility Interface of Photovoltaic (PV) Systems," IEEE Standards, 929-2000.

[23] Ustun T.S., Mekhilef S., "Power Line Compensation Study of a Static Synchronous Series Compensator (SSSC) Based on Soft Switching 48pulse PWM Inverter," Australian Journal of Basic and Applied Sciences, AJBAS April-June 2009, Vol. 3 No. 2, pp. 1301-1314, 2009.

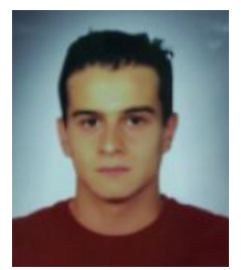

Taha Selim Ustun received his Bachelor's degree in Electrical and Electronics Engineering from the Middle East Technical University, TURKEY in 2007. He is currently a M. S. candidate in the Department of Electrical Engineering, University Malaya, Malaysia. His research interests are power electronics, power systems and FACTS devices.

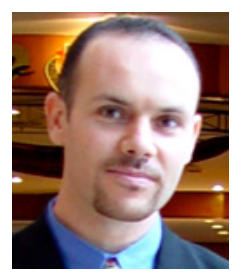

Saad Mekhilef received a B Eng. Degree in Electrical Engineering from the University of Setif, Algeria in 1995 and a M Eng.Sc. and PhD from the University Malaya in 1998 and 2003 respectively. He is currently Associate Professor in the Dept. of Electrical Engineering, University Malaya. Dr. Mekhilef is the author and co-author of more than 100 publications in international journals and proceedings. He is actively involved in industrial consultancy for major corporations in power electronics projects. His research interests include industrial electronics, power conversion techniques, control of power converters, renewable energy systems and energy efficiency. 